\title{
Inovação organizacional como alternativa para a eficiência na prestação de serviços jurisdicionais
}

Isabelle de Baptista

Professora do Curso de Direito da Universidade Federal de Mato Grosso/Campus Araguaia

Doutoranda em Administração pela Universidade Nove de Julho/UNINOVE

https://orcid.org/0000-0003-2640-6706

isabelledebaptista@hotmail.com

Leonel Cezar Rodrigues

Pós-Doutorado em Administração pela Old Dominion University, VA (USA). Professor titular e pesquisador do Programa de Doutorado em Administração da Universidade Nove de Julho PPGA/UNINOVE e Coordenador do Programa de Doutorado Interinstitucional em Administração e de Relações Internacionais do PPGA/UNINOVE.

https://orcid.org/0000-0001-5966-1063

leonelcz@gmail.com

Priscila Rezende da Costa

Doutora em Administração pela Universidade de São Paulo, FEA USP. Professora titular e pesquisador do Programa de Doutorado em Administração da Universidade Nove de Julho - PPGA/UNINOVE https://orcid.org/0000-0002-7012-0679

priscilarezende@yahoo.com.br

\section{Editor Científico: José Edson Lara}

Organização Comitê Científico

Double Blind Review pelo SEER/OJS

Recebido em 03.04.2018

Aprovado em 29.08.2019

Este trabalho foi licenciado com uma Licença Creative Commons - Atribuição - Não Comercial 3.0 Brasil 


\title{
Resumo
}

Muitas pesquisas têm sido conduzidas sobre a definição e evolução do tema inovação organizacional, como também sobre o impacto deste tipo de inovação no desempenho organizacional. Considerando as deficiências na prestação de serviços pelo Poder Judiciário brasileiro, como o grande número de processos a cargo de uma estrutura administrativa insuficiente, observa-se as possíveis vantagens da adoção e implementação da inovação organizacional na prestação de serviços jurisdicionais. Por isso, além de explanar sobre a inovação organizacional, exploramos o tema da inovação na gestão pública brasileira, e em específico, na gestão do Poder Judiciário. Desta forma, pretende-se, analisar a possibilidade da inovação organizacional contribuir para melhoria dos serviços prestados pelo Poder Judiciário.

Palavras-Chave: Inovação Organizacional; Prestação de Serviços Jurisdicionais; Poder Judiciário Brasileiro; Inovação no Setor Público

\section{Organizational innovation as an alternative to efficiency in the provision of jurisdictional services}

\begin{abstract}
There are many researches that explore the definition and evolution of theme organizational innovation as well as the impact of this type of innovation on organizational performance. Considering the limitations and issues on the provision of services on the Brazilian Judiciary, which presents a high number of legal actions and an inefficient administrative structure, it is expectable that organizational innovation can lead to positive results on the provision of legal services in our Judiciary. For this reason, apart from describing the concepts of organizational innovation, we explore the theme of organizational innovation in public administration, more specifically, in the Judiciary. Therefore, we analyze how the adoption and implementation of organizational innovation can lead to better and more eficiente services in the Judiciary.
\end{abstract}

Keywords: Organizational Innovation; Provision of Legal Services; Brazilian Judiciary; Innovation in Public Sector

\section{Innovación organizacional como alternativa a la eficiencia en la prestación de servicios jurisdiccionales}

\section{Resumen}

Hay muchas investigaciones que exploran la definición y evolución del tema de la innovación organizacional, así como el impacto de este tipo de innovación en el desempeño organizacional. Teniendo en cuenta las limitaciones y problemas en la prestación de servicios en el Poder Judicial brasileño, que presenta un alto número de acciones legales y una estructura administrativa ineficiente, es de esperar que la innovación organizacional pueda conducir a 
resultados positivos en la prestación de servicios legales en nuestro Poder Judicial. Por esta razón, además de describir los conceptos de innovación organizacional, exploramos el tema de la innovación organizacional en la administración pública, más específicamente, en el Poder Judicial. Por lo tanto, analizamos cómo la adopción e implementación de la innovación organizacional puede conducir a mejores y más eficientes servicios en el Poder Judicial.

Palabras clave: Innovación organizacional; Prestación de servicios legales; Poder Judicial brasileño; Innovación en el sector público

\section{Introdução}

A inovação organizacional consiste, em geral, no desenvolvimento, implantação de uma ideia ou comportamento nos processos internos, contribuindo para importantes mudanças na forma de gestão de uma organização (OECD, 2005). Promovem mudanças nas estruturas organizacionais, administrativas, nas práticas de gestão que criam valor para a organização (Birkinshaw, Hamel, \& Mol, 2008; Damanpour \& Aravind, 2011; Kimberly \& Evanisko, 1981). Inclusive, diversos estudos apontam as vantagens da implantação da inovação organizacional (Armbruster, Bikfalvi, Kinkel, \& Lay, 2008; Damanpour \& Schneider, 2009; Frambach \& Schillewaert, 2002).

Considerando as diversas vantagens apontadas pela literatura, pretende-se analisar como a inovação organizacional pode contribuir positivamente para melhoria da eficiência dos serviços prestados pelo Poder Judiciário no Brasil.

A Constituição da República Federativa do Brasil (CRFB) promoveu a significativa ampliação de direitos, reconhecimento de novos direitos, maior possibilidade de acesso à justiça, a multiplicação do número de varas e comarcas em todo o país, implantação e ampliação dos processos judiciais eletrônicos, maior independência e ampliação na atuação do Ministério Público, fortalecimento das defensorias públicas, entre tantas outras inovações que propiciaram, nas últimas décadas, um crescimento expressivo da atuação do Poder Judiciário em todo o Brasil.

E a consequência imediata da ampliação das competências do Judiciário foi a sobrecarga de demandas judiciais que impactou sobremaneira a prestação de serviços, já que poucas e profundas mudanças de natureza administrativa foram feitas. Desta forma, de um lado, permitiu-se uma atuação expressiva por parte do Judiciário, mas, de outro lado, é impossível observar alguma referência positiva à atuação do sistema judicial brasileiro, no que tange à eficaz prestação de serviços (Abramo, 2010; CNJ, 2016; Sadek, 2004; Taylor, 2005). 
Taylor (2005) chega a apontar como "enigma" a capacidade que o Judiciário possui de ser um sistema judicial forte, uma vez que é capaz controlar o poder político e garantir o cumprimento de suas decisões, e, ao mesmo tempo, conviver com o sistema quase inoperante e com expressivas deficiências administrativas.

Ademais, para se ter uma noção do crescimento do Poder Judiciário em todo o país, em 1988, ano da promulgação da vigente Constituição da República Federativa do Brasil, foram ajuizadas 350 mil novas ações; em 2001, 12 milhões; em 2011, 26,3 milhões; em 2015, 27.280.287 milhões de novas ações. Em 1988, em todo o Brasil, haviam 4.900 juízes; em 2015, 17.338. Portanto, o número de juízes não chegou a quadriplicar, ao passo que o número de novas ações cresceu 80 vezes (CNJ, 2016).

O que se conclui é que "o aumento das demandas e o crescimento do Poder Judiciário trouxeram uma visível incapacidade para atender todos os conflitos que lhe foram submetidos a julgamento" (Medeiros, 2006).

O crescimento da prestação de serviços pelo Poder Judiciário não foi acompanhado por uma mudança organizacional capaz de propiciar a eficiência na prestação da atividade jurisdicional, vez que esse incremento encontrou uma estrutura pouco ou rudimentarmente aparelhado, com cultura organizacional, instrumentos e procedimentos ultrapassados (Medeiros, 2006, p. 63).

Vale ressaltar que o trâmite de processos é definido por legislações específicas, assim, pouca intervenção pode ser feita, a não ser por alteração legislativa. Já o que pode ser realizado pelos tribunais é o fomento da melhoria nos processos internos, na introdução da inovação na esfera administrativa, a fim de contribuir para uma melhor prestação de serviços, de forma mais ágil, célere e transparente (Stumpf, 2008).

Conforme a literatura (Armbruster et al., 2008; Damanpour, 1991; Damanpour \& Evan, 1984; Frambach \& Schillewaert, 2002), entende-se que o fomento à inovação organizacional pode contribuir para o aprimoramento da performance organizacional. Através do fomento à inovação organizacional, complexas mudanças nas estruturas internas do Poder Judiciário, como maior controle nos procedimentos administrativos, nas estruturas das relações de trabalho, na hierarquia, no fluxo de comunicação, no sistema de gestão, na política de remuneração, na organização e distribuição de trabalho (Medeiros, 2006; Stumpf, 2008). 
Destaca-se que a implantação das metas pelo Conselho Nacional de Justiça - CNJ configura um grande exemplo exitoso de inserção de inovações organizacionais que contribuem para a melhoria da prestação de serviços jurisdicionais pelo Poder Judiciário brasileiro (CNJ, 2016).

Este ensaio teórico tem por objetivo explanar sobre a definição e evolução dos estudos em inovação organizacional, como também sobre o impacto deste tipo de inovação na prestação de serviços jurisdicionais.

\section{Referencial Teórico}

\subsection{Inovação organizacional}

Com o intuito de estimular, fomentar e padronizar a inovação por parte das organizações e, com isso, contribuir para o desenvolvimento econômico, em 2005, a Organização para a Cooperação e Desenvolvimento Econômico - OCDE - elaborou o Manual de Oslo que conceituou a inovação como "a implementação de um produto (bem ou serviço) novo ou significativamente melhorado, ou um processo, ou um método de marketing, ou um novo modelo organizacional nas práticas de negócios, na organização do local de trabalho ou nas relações externas" (OECD, 2005).

O Manual de Oslo contribuiu para uma ampliação significativa do conceito de inovação, que pode ocorrer de diversas formas: a inovação pode ser implementada no produto ou serviço; no processo em que o produto ou serviço é criado e entregue; na forma como um produto ou serviço é apresentado e introduzido no seu mercado; e também na organização, nos procedimentos internos, na mudança de paradigmas e comportamentos existentes dentro da própria organização que importem em ganhos econômicos e sociais (OECD, 2005).

Também de acordo com o Manual de Oslo, a capacidade de inovação está atrelada a várias especificidades que as organizações devem possuir e combiná-las de maneira eficiente. Para que consigam promover uma inovação, devem alterar significativamente sua estrutura, implantar técnicas gerenciais avançadas e implantar orientações estratégicas novas ou substancialmente alteradas (OECD, 2005). Portanto, a inovação organizacional compreende a abertura que as organizações devem ter para a criação, fomento e/ou modificação de práticas internas que sejam capazes de gerar valor ou novos comportamentos internos à organização. 
Araújo, Modolo, e Carneiro (2018) realizaram um estudo bibliométrico das publicações sobre inovação organizacional, entre os anos de 1960 e 2015, em periódicos indexados na base de dados Web of Science. Neste estudo, as co-citações destas publicações foram classificadas em oito categorias: comportamento inovador e inovação técnica, tecnologia, inovação tecnológica e ambiente competitivo, instrumentos usados na medição de comportamento inovador, tipos de inovação, antecedentes de criatividade e inovação, instrumentos usados na pesquisa em inovação, e antecedentes de inovação organizacional.

Estas categorias agrupam as principais referências utilizadas em pesquisas sobre inovação organizacional. Dentre os artigos seminais, destacam-se os estudos (Birkinshaw et al., 2008; Damanpour \& Aravind, 2011; Kimberly \& Evanisko, 1981) que sugerem avançadas formas de gerenciamento, estruturas organizacionais significativamente modificadas e aperfeiçoadas que melhor atendam às demandas estratégicas das organizações. Para os autores, as inovações organizacionais promovem mudanças nas estruturas organizacionais, administrativas, nas ráticas de gestão que criam valor para a organização.

É importante ressaltar, que as publicações sobre inovação organizacional apresentaram um significativo aumento a partir de 2000. Aliás, Araújo et al. (2018) denotam uma tendência maior de crescimento do que de declínio da prominência deste tema.

Considerando a significativa capacidade de efetuar mudanças gerenciais e no desenvolvimento de novas práticas organizacionais, a inovação organizacional é uma précondição para a utilização bem-sucedida de recursos investidos e de novas tecnologias implantadas, assim, as inovações organizacional e tecnológica se entrelaçam (Lam, 2004). Evangelista e Vezzani (2010), em estudos empíricos realizados, demonstram que a implantação conjunta de inovações tecnológica e organizacional são os motores do desenvolvimento econômico das organizações e conferem clara vantagem competitiva.

As inovações serão exitosas se acompanhadas de profundas mudanças na estrutura interna das organizações. Nesse sentido, Frambach e Schillewaert (2002) destacam que o processo de adoção da inovação passa, antes, pela aceitação de um novo produto, serviço ou ideia. Esse processo possui duas fases: a primeira de iniciação em que a organização toma consciência da inovação, forma uma atitude em relação a ela e avalia o novo produto. Em seguida, ocorre a fase da implementação em que a organização decide utilizar a inovação. Para os autores, a inovação organizacional é fundamental por estabelecer a aceitação, assimilação e incorporação da inovação dentro da organização (Frambach \& Schillewaert, 2002). 
Armbruster et al. (2008) também destacam que muitos estudos comprovam as vantagens da inovação organizacional no desempenho dos negócios. A inovação organizacional atua como pré-requisitos e facilitadores de um uso eficiente de inovações técnicas de produtos e processos. Além disso, a inovação organizacional apresenta pode levar a maior produtividade, qualidade e flexibilidade nas organizações (Armbruster et al., 2008).

Por sua vez, com foco na compreensão de como o processo de inovação ocorre, mas pela perspectiva de dentro da organização, Knight (1967) aponta que a inovação ocorre dentro de um contexto organizacional, daí a necessidade de se olhar para dentro da organização e analisar o que se passa por dentro dela. Devem ser estimulados a criação de mecanismos que permitam aos sujeitos integrantes da organização, a liberdade para identificar e perseguir problemas, oferecer canais de comunicação abertos e encorajar pontos de vista diferentes e incomuns (Knight, 1967). Uma organização representa um sistema adaptativo que deve melhorar continuamente seu desempenho para se manter na sociedade moderna, daí a necessidade da organização de hoje estar sempre e em constante evolução. A inovação organizacional é uma das categorias da inovação que compreende a alteração das tarefas de trabalho, das relações de autoridade, do sistema de comunicação ou do sistema de recompensas formais na organização. Portanto, por meio da inovação organizacional, através de significativas mudanças nas estruturas internas, que a ideia inovadora é implementada nas organizações (Knight, 1967).

Se de um lado a inovação técnica compreende a implementação de uma ideia para um novo produto, um novo serviço ou a introdução de novos elementos no processo de produção ou no serviço de uma organização, já as inovações organizacionais (também chamadas de administrativas) são aquelas que ocorrem dentro do sistema social da organização. E por sistema social compreende-se as relações entre as pessoas que interagem para atingir um objetivo ou tarefa particular, bem como as regras, papéis, procedimentos e estruturas relacionados à comunicação e intercâmbio entre as pessoas e entre o ambiente e as pessoas (Damanpour, 1991; Damanpour \& Evan, 1984).

Na pesquisa de Meyer e Goes (1988), o principal objetivo foi analisar o processo de assimilação da inovação, o por quê e como as organizações evoluem, adotam e implementam inovações. Para os Meyer e Goes (1988), a assimilação da inovação compreende um processo organizacional que, primeiro, é iniciado quando membros da organização individual acordam sobre o desenvolvimento da inovação; segundo, decidem pela aquisição da inovação; e, em seguida, concretizam a aceitação, utilização e institucionalização da inovação. Ou seja, a 
inovação organizacional é fundamental para o processo de implantação de inovações tecnológicas.

Camisón e Villar-López (2011), tendo como parâmetro o conceito de inovação organizacional contido no Manual de Oslo (OCDE, 2005), estabelecem que as inovações organizacionais envolvem a implementação de novos métodos para organizar rotinas e procedimentos de trabalho. As inovações na organização do local de trabalho envolvem a implementação de novos métodos para distribuir responsabilidades e tomada de decisões entre os funcionários para a divisão de trabalho, bem como novos conceitos para a estruturação de atividades.

Inovação organizacional também compreende a implementação de novos métodos de organização nas relações externas de uma organização com outras organizações ou instituições públicas (Camisón \& Villar-López, 2011).

A memória organizacional e as capacidades de aprendizagem são importantes fatores antecedentes à inovação organizacional que compreende, para Camisón e Villar-Lopez (2011), a inovação organizacional e o marketing. Os resultados da pesquisa aplicada (Camisón \& Villar-López, 2011) sugerem que a memória organizacional e as capacidades de aprendizagem têm efeitos positivos na inovação organizacional. As capacidades baseadas no conhecimento são fundamentais para o desenvolvimento de inovações não-técnicas.

Os antecedentes, como a memória organizacional, são decisivos nesse processo, pois podem servir de inspiração para a inovação organizacional. A memória organizacional pode favorecer a introdução de novas práticas comerciais, como a geração de banco de dados, lições e outros conhecimentos aprendidos com o tempo. A memória organizacional também pode fornecer informações sobre o histórico organizacional que podem ser consideradas nas tomadas de decisões (Camisón \& Villar-López, 2011).

Com o intuito de distinguir da inovação tecnológica, a inovação organizacional inicialmente foi denominada de inovação administrativa (Daft, 1978; Damanpour \& Evan, 1984; Kimberly \& Evanisko, 1981) focado nas mudanças internas nas organizações, necessárias para o sucesso da implantação de alguma inovação. A inovação administrativa, diferente da inovação do produto ou serviço e da inovação técnica, é orientada para a eficiência e eficácia dos processos de gestão e sistemas administrativos das organizações (Damanpour \& Aravind, 2011). 
Em seguida, a terminologia passou a incluir a expressão "gestão", ressaltando a importância que mudanças no gerenciamento das organizações (Birkinshaw et al., 2008; Damanpour \& Aravind, 2011; Hwang, 2004).

A inovação gerencial altera os processos e práticas tradicionais de gerenciamento, ou simplesmente "muda como os gerentes fazem o que fazem" (Damanpour \& Aravind, 2012). Compreende, segundo Damanpour e Aravind (2012), novas abordagens de conhecimento para a realização da atividade de gerenciamento e novos processos que produzem mudanças na estratégica, estrutura, procedimentos administrativos e sistemas de organização, proporcionando a renovação, adaptação e eficácia da organização

Dessa forma, a inovação gerencial compreende as inovações em novas estruturas organizacionais, nos sistemas administrativos, nas práticas gerenciais, processos e técnicas que podem criar valor para as organizações, com mudanças nas regras e rotinas pelas quais o trabalho é feito (Damanpour \& Aravind, 2011).

Damanpour e Aravind (2012) identificam alguns tipos de inovação gerencial como (i) a que a inovação que ocorre na estratégia ou na estrutura da organização. A estratégia compreende os objetivos, atuação e alocação de recursos a longo prazo pela organização. Já a estrutura compreende a forma como a organização divide suas atividades e consegue a coordenação entre elas; (ii) inovação nas formas e nos procedimentos da organização; (iii) inovação promovida pela utilização de tecnologias da informação (TI); e, (iv) inovações radicais, consideradas aquelas pertubadoras, que criam descontinuidade, provocam mudanças fundamentais nos resultados ou nas atividades internas da organização e, por isso, alteram o status quo (Damanpour \& Aravind, 2011).

Porém, mesmo com um crescimento expressivo e ininterrupto, a literatura sobre inovação organizacional é bem dispersa, o que dificulta a formulação de um quadro teórico consistente que permite analisar a performance da inovação e seu reflexo sobre o desempenho da organização. Damanpour (1991) analisou as diversas pesquisas em inovação e identificou variações e instabilidade nos resultados obtidos e, por meio de meta-análise da relação entre inovação organizacional e treze variáveis independentes, esquematizou os principais resultados conforme a figura 1 . 


\begin{tabular}{|c|c|}
\hline $\begin{array}{l}\text { Variáveis } \\
\text { independe } \\
\text { ntes }\end{array}$ & Razões para as expectativas \\
\hline $\begin{array}{l}\text { Especializaç } \\
\text { ão }\end{array}$ & $\begin{array}{l}\text { Maior variedade de especialistas proporcionaria uma base de conhecimento mais ampla e } \\
\text { aumentaria a fertilização de ideias. }\end{array}$ \\
\hline $\begin{array}{r}\text { Diferenciaçã } \\
\text { o funcional } \\
\end{array}$ & $\begin{array}{l}\text { A formação de coalizões de profissionais de diferentes especializações contribui para } \\
\text { introdução de mudanças nos sistemas técnicos e administrativos. }\end{array}$ \\
\hline $\begin{array}{l}\text { Profissionali } \\
\text { smo }\end{array}$ & Aumenta o limite das atividade de fronteira, a autoconfiança e o comprometimento. \\
\hline $\begin{array}{l}\text { Formalizaçã } \\
\text { o }\end{array}$ & $\begin{array}{l}\text { A flexibilidade e a pouca ênfase nas regras do trabalho facilitam a inovação. A baixa } \\
\text { formalização permite a abertura, que incentiva novas idéias e comportamentos. }\end{array}$ \\
\hline $\begin{array}{l}\text { Centralizaçã } \\
\text { o }\end{array}$ & $\begin{array}{l}\text { A concentração da autoridade de decisão impede soluções inovadoras, enquanto a dispersão } \\
\text { do poder é necessária para a inovação. Os ambientes de trabalho participativo facilitam a } \\
\text { inovação aumentando a consciência, compromisso e envolvimento dos membros } \\
\text { organizacionais. }\end{array}$ \\
\hline $\begin{array}{l}\text { Atitude } \\
\text { gerencial } \\
\text { em relação } \\
\text { à mudança }\end{array}$ & $\begin{array}{l}\text { A atitude favorável dos gerentes em relação à mudança leva a um clima interno propício à } \\
\text { inovação. O apoio gerencial para a inovação é especialmente necessário na fase de } \\
\text { implementação, quando a coordenação e a resolução de conflitos entre indivíduos e } \\
\text { unidades são essenciais. }\end{array}$ \\
\hline $\begin{array}{ll}\text { Tempo de } \\
\text { serviço do } \\
\text { gerente }\end{array}$ & $\begin{array}{l}\text { A longevidade dos gerentes em seus empregos fornece legitimidade e conhecimento sobre } \\
\text { como realizar tarefas, gerenciar processos políticos e obter resultados desejados. }\end{array}$ \\
\hline $\begin{array}{l}\text { Conheciment } \\
\text { o técnico } \\
\text { recursos }\end{array}$ & $\begin{array}{l}\text { Quanto maior o conhecimento técnico, mais fácilmente as novas idéias técnicas podem ser } \\
\text { compreendidas, implementadas e desenvolvidas. }\end{array}$ \\
\hline $\begin{array}{l}\text { Intensidade } \\
\text { administrat } \\
\text { iva }\end{array}$ & $\begin{array}{l}\text { Uma maior proporção de gerentes facilita a inovação porque a adoção bem-sucedida de } \\
\text { inovações depende em grande parte da liderança, suporte e coordenação que os gerentes } \\
\text { fornecem. }\end{array}$ \\
\hline $\begin{array}{l}\text { Falta de } \\
\text { recursos }\end{array}$ & $\begin{array}{l}\text { Os recursos mais escassos permitem que uma organização compre inovações, absorva o } \\
\text { fracasso, suporte os custos de instituir inovações e explore novas idéias antes de uma } \\
\text { necessidade real. }\end{array}$ \\
\hline $\begin{array}{l}\text { Comunicaçã } \\
\text { o externa }\end{array}$ & $\begin{array}{l}\text { Mapeamento ambiental e das atividades profissionais dos membros extraorganizacionais } \\
\text { podem trazer idéias inovadoras. Organizações inovadoras trocam informações com seus } \\
\text { ambientes efetivamente. }\end{array}$ \\
\hline $\begin{array}{l}\text { Comunicaçã } \\
\text { o interna }\end{array}$ & $\begin{array}{l}\text { Facilita a dispersão de idéias dentro de uma organização e aumenta a quantidade de } \\
\text { diversidade, o que resulta em fertilização cruzada de idéias. Também cria um ambiente } \\
\text { interno favorável à sobrevivência de novas idéias. }\end{array}$ \\
\hline $\begin{array}{l}\text { Diferenciaçã } \\
\text { o vertical }\end{array}$ & $\begin{array}{l}\text { Muitos níveis hierárquicos nos canais de comunicação, fazem a comunicação entre níveis } \\
\text { mais difícil e inibe o fluxo de idéias inovadoras. }\end{array}$ \\
\hline
\end{tabular}

Revista Gestão \& Tecnologia 
Estudos indicam que a implementação de inovação organizacional resulta em desenvolvimento de novos produtos, serviços e processos. $\mathrm{Na}$ verdade, a inovação organizacional tem relação direta com inovação de processos e inovação de produtos. Inclusive, a combinação destes três tipos de inovação pode resultar em aumento de desempenho organizacional (Camisón \& Villar-López, 2014).

\subsection{O Poder Judiciário brasileiro}

O Brasil, enquanto nação independente, possui uma organização política definida na Constituição da República Federativa do Brasil (CRFB). É neste documento, de natureza jurídica e política, que define, em seu artigo $2^{\circ}$, que os poderes que integram a República, são o Legislativo, Executivo e Judiciário, todos independentes e harmônicos entre si.

Em relação à natureza política da Constituição, Dobrowolski (1990) ensina que compreende uma energia criada pela sociedade, com poder de governo e condução, a fim de que os objetivos desta sociedade sejam cumpridos. A Constituição divide o comando da sociedade em três Poderes: Legislativo, Executivo e Judiciário - a clássica tripartição (Dobrowolski, 1990).

Por independência, entende-se que os poderes da República possuem uma esfera de atuação específica, ou seja, em determinadas matérias, também definidas constitucionalmente, os poderes atuam exclusivamente, sob pena de exorbitar de suas competências. Ademais, cada poder gere recursos financeiros necessários para sua manutenção. A independência, portanto, compreende um rol de competências exclusivas de cada Poder e a capacidade de gerir, de forma autônoma, os recursos financeiros necessários à sua manutenção (Bonavides, 2011; Canotilho, 2003; Marmelstein, 2013; Morais, 2001).

O Poder Judiciário, além de ser um poder de Estado e que cumpre a função política de limitação do poder estatal, é um grande prestador de serviços públicos, através de sua maior função que é a jurisdicional, que compreende a função do Estado que tem por escopo a atuação da vontade concreta da lei por meio da substituição, pela atividade dos órgãos públicos, da atividade de particulares ou de outros órgãos públicos, já no afirmar a existência da vontade da lei, já no torná-la, praticamente efetiva (Chiovenda, 2002). 
Por meio da função jurisdicional, o Poder Judiciário exerce sua função típica ao substituir as vontades dos indivíduos e decidir conforme o ordenamento jurídico. Vale destacar que esta decisão, após percorrer o rito processual definido em lei, torna-se, em regra, definitiva e irrecorrível. Por isso, imperioso que o Poder seja independente e imparcial, a fim de aplicar aos casos concretos um julgamento que respeite as normas constitucionais e as leis, concretizando a justiça social, aproximando as competências legais à satisfação dos conflitos e garantindo direitos aos cidadãos.

Integram a estrutura do Poder Judiciário, o Supremo Tribunal Federal, o Conselho Nacional de Justiça, o Superior Tribunal de Justiça, o Tribunal Superior do Trabalho, os Tribunais Regionais Federais e Juízes Federais, os Tribunais e Juízes do Trabalho, os Tribunais e Juízes eleitorais, os Tribunais e Juízes Militares, os Tribunais e Juízes dos Estados e do Distrito Federal e Territórios, nos termos do artigo 92, CRFB.

A CRFB foi um marco no reconhecimento de direitos e deveres constitucionais. Fruto de complexo processo de redemocratização, incorporou direitos individuais, típicos do liberalismo, como também direitos sociais e coletivos, como a garantia de melhores condições de trabalho; proteção ao desemprego; à uma vida digna com alimentação, vestuário, habitação, lazer, assistência médica, educação; proteção da previdência social, em caso de acidente, doença, invalidez ou velhice, entre tantos outros. Outro marco foi o reconhecimento de direitos que atingem toda a coletividade como a proteção ambiental, a proteção decorrente das relações de consumo, o direito à paz e ao desenvolvimento (Bonavides, 2011; Canotilho, 2003; Marmelstein, 2013; Morais, 2001). Além disso, a CRFB trouxe um complexo sistema de controle de constitucionalidade das leis e atos normativos.

Desta forma, verifica-se que a CRFB impôs profundas modificações em toda a estrutura jurídica brasileira, em especial propiciou, como nunca antes, uma incomparável judicialização dos mais diversos conflitos, reconheceu novos direitos outrora negados ou inexistentes no Brasil (Bonavides, 2011).

A CRFB permitiu o acesso à justiça por meio de instrumentos facilitadores como a isenção de custas processuais para indivíduos hipossuficientes econômicos, multiplicação do número de varas e comarcas em todo o país, implantação de juizados especiais, implantação e ampliação dos processos judiciais eletrônicos, maior independência e ampliação na atuação do Ministério Público, fortalecimento das defensorias públicas, entre tantas outras inovações 
que propiciaram, nas últimas décadas, um crescimento expressivo da atuação do Poder Judiciário em todo o Brasil (Bonavides, 2011).

Diante desse cenário, o Poder Judiciário precisou sofrer inúmeras modificações para conseguir atender a essa maior demanda de processos, de direitos, de exigências impostas tanto por parte de legislações como pela sociedade, cada vez mais consciente de seus direitos e obrigações.

Também decorre da CRFB o protagonismo que o Judiciário passou a exercer diante dos outros poderes do Estado. Diante do esgotamento dos poderes Legislativo e Executivo, no século XXI, além das ações interindividuais, o principal papel do Judiciário é dar concreção, dar efetividade aos direitos fundamentais, direitos estes compreendidos como patrimônios da humanidade (Lewandowski, 2009).

O modelo institucional, segundo Sadek (2004), “conferiu ao Judiciário um papel político relevante, legitimando a atuação pública da magistratura e transformando a arena judicial em um espaço que abriga e arbitra o confronto entre as forças políticas”. Assim, a disputa política tem como palco não apenas o Parlamento, mas também as varas e tribunais de justiça (Sadek, 2004).

Assim, a consequência imediata do reconhecimento de novos direitos, deveres e ampliação expressiva das atribuições constitucionais do Poder Judiciário, foi o significativo aumento das ações.

Todavia, a prestação de serviços pelo Judiciário encontra poucas referências positivas, seja na literatura, seja nas pesquisas de opinião, seja nos números divulgados pelo Conselho Nacional de Justiça (Abramo, 2010). A crítica mais comum é em relação ao tempo que os tribunais levam para decidir.

Embora os tribunais tenham desempenhado um importante papel político nas últimas décadas, restringindo e alterando a política federal em uma variedade de assuntos, o sistema judicial brasileiro foi simultaneamente rotulado de "disfuncional" (Taylor, 2005).

Taylor (2005) aponta como um "enigma" a capacidade do Brasil possui um sistema judicial forte - capaz de verificar o governo, reverter a política e garantir o cumprimento de suas decisões - ao mesmo tempo conviver com um sistema judicial quase inoperante, proporcionando poucas garantias credíveis ao cidadão médio de rápido recurso legal contra as políticas públicas do governo. Além disso, os tribunais proporcionam uma resolução pacífica de disputas políticas importantes, mas, por outro lado, a maneira pela qual o sistema judicial opera exclui uma grande parte dos cidadãos. 
Segundo dados do Conselho Nacional de Justiça, órgão administrativo que integra o Poder Judiciário com a finalidade de executar as práticas de controle administrativo interno, expede, todos os anos, o relatório "Justiça em Números", de 2016 com a análise dos números de 2015. Para se ter uma noção do crescimento do Poder Judiciário em todo o país, em 1988, ano da promulgação da vigente Constituição da República Federativa do Brasil, foram ajuizadas 350 mil novas ações; em 2001, 12 milhões; em 2011, 26,3 milhões; em 2015, 27.280.287 milhões de novas ações. Em1988, em todo o Brasil, haviam 4.900 juízes; em 2015, 17.338. Portanto, o número de juízes não chegou a quadriplicar, ao passo que o número de novas ações cresceu 80 vezes (CNJ, 2016).

De um lado, verifica-se uma ampliação significativa das atribuições do poder Judiciário, de outro, uma estrutura administrativa incapaz de solucionar, com eficiência ao grande número de demandas, gerando o que Sadek (2004) destacou como outros dois aspectos que afetam o Judiciário: 1) a justiça transformou-se em questão percebida como problemática por amplos setores da população, da classe política e dos operadores do Direito, passando a constar da agenda de reformas; 2) tem diminuído consideravelmente o grau de tolerância com a baixa eficiência do sistema judicial e, simultaneamente, aumentado a corrosão no prestígio do Judiciário

Considerando o crescimento das taxas de industrialização, urbanização, consciência de direitos e credibilidade do aparato judicial, a consequência imediata é o aumento significativo da conversão dos conflitos e ações judiciais (Sadek, 2004).

Diante desse cenário, Sadek (2004) afirma a existência de um paradoxo no sistema judicial brasileiro que denominou "demandas de menos e demandas de mais. (...) Ou seja, de um lado, expressivos setores da população acham-se marginalizados dos serviços judiciais. De outro, há os que usufruem com excesso da justiça oficial, gozando das vantagens de uma máquina lenta, atravancada e burocratizada".

Dessas deficiências, destaca-se, ano a ano, o crescimento do número de ações judiciais, que acabam se avolumando diante da estrutura burocratizada e engessada pela legislação e pela cultura organizacional. A estrutura para o processamento de demandas, para Sadek (2004), é a dimensão mais visível do que se convencionou chamar de crise do Judiciário, pois deixa evidente o quanto a estrutura é ineficaz, incapaz de dar soluções em tempo razoável e em custos acessíveis a todos. Ou seja, o aumento da demanda não foi acompanhada de um aumento da capacidade do Judiciário (Sadek, 2004). 
Diversos outros fatores são apontados de forma a explicar essa crítica situação. O número insuficiente de juízes é um dos fatores mais importantes para justificar a baixa agilidade no desempenho do Judiciário. Outro fator é a permanência de traços aristocráticos na instituição. "O figurino da instituição tem mostrado um verdadeiro "descompasso entre o valorizado pela instituição e as mudanças vividas pela sociedade", o que acaba por favorecer a imagem negativa da magistratura frente à população (Sadek, 2004, p. 22).

Outros motivos apontados são "a escassez de recursos materiais e/ou deficiências na infraestrutura; o conjunto de problemas relacionados à esfera legislativa e aos ritos processuais" (Sadek, 2004, p. 23).

Em estudo realizado sobre a produção científica a respeito do desempenho do Judiciário, entre 1992 a 2011, em diversas bases de dados que reúnem a grande maioria das publicações científicas. Da revisão de literatura realizada, demonstrou-se que o tema é pouco explorado, principalmente na área da administração pública e que uma agenda de pesquisa ainda precisa ser construída (Gomes \& Guimarães, 2013).

De um lado inúmeras são as deficiências existentes na prestação de serviços pelo poder Judiciário, mas de outro lado, poucas pesquisas científicas adentram, em profundidade, ao estudo de seu desempenho. Gomes e Guimarães (2013) destacam os seguintes fatores:

- desempenho de juízes - este tema merece atenção especial, pois, em geral, as pesquisas realizadas consideram-se as atividades dos juízes a essência de todo o trabalho e desempenho judicial (Gomes \& Guimarães, 2013);

- recursos - os recursos financeiros e humanos foram analisados nas pesquisas selecionadas. Quanto aos recursos financeiros, a principal constatação é que o aumento desse tipo de recurso não garante aumento de desempenho; ao passo que em relação dos recursos humanos no desempenho do Judiciário é controversa, já que parte das pesquisas indicam que a quantidade disponível de trabalhadores, inclusive juízes, é fundamental para o desempenho no setor, enquanto outra parte conclui que esta importância é relativa (Gomes \& Guimarães, 2013);

- $\quad$ procedimentos legais e administrativos - segundo Gomes e Guimarães (2013), as pesquisas apontam como obstáculos à melhoria do desempenho judicial a falta de padronização e o excesso de formalismo em procedimentos legais e administrativos. Os resultados também são convergentes ao apontar a adoção de novas tecnologias como importantes mecanismos para diminuir o tempo de duração de procedimentos, além de aumentar a segurança das informações e ampliar o acesso de usuários (Gomes \& Guimarães, 2013). 
- comparação entre unidades - algumas pesquisas investigaram o desempenho judicial com base na comparação de tribunais ou sistemas judiciários nacionais. Para os autores, esse tipo de pesquisa permite identificar quais unidades devem ser imitadas e quais devem buscar melhorias em seus processos produtivos. A comparação entre unidades geralmente tem como base o conceito de eficiência técnica ou produtividade (Gomes \& Guimarães, 2013).

As consequências das deficiências do sistema judicial recai sobre todo o conjunto social. (Castro, 2011) destaca que o funcionamento precário do sistema de Justiça, inclusive, promove consequências negativas sobre a economia, como no mercado de crédito, spreads bancários, indicadores do mercado de trabalho e formação bruta de capital e inovação tecnológica ( Fachada, Figueiredo, \& Lundberg, 2003; Fraisse, Kramarz, \& Prost, 2009; Mansfield, 1994, 1995).

\subsection{A inovação organizacional no Poder Judiciário brasileiro}

O tema de inovação na administração pública federal tem ganhado importância nos últimos anos. Tal fato, é comprovado pela criação do Concurso Inovação na Gestão Pública Federal, pela Escola Nacional de Administração Pública (ENAP). Este concurso ocorre desde 1996, promovendo o fomento e a análise de iniciativas de inovação no setor público (Camões, Severo, \& Cavalcante, 2017).

Ao analisar, as premiações do concurso, Camões et al. (2017) concluem que práticas focadas em melhorias de processos de trabalho em órgão públicos, são as mais recorrentes, como também as mais premiadas. Inclusive os autores observam que os órgãos públicos que prestam serviços diretamente à população são aqueles que mais implementam inovação para melhorias de processos de trabalho, devido a demanda por melhores níveis de qualidade.

Diante desse cenário, o Poder Judiciário utiliza algumas estratégias para enfrentar o congestionamento dos tribunais, como o investimento em tecnologias da informação e comunicação, contratação de pessoal como juízes e assistentes administrativos, incentivo aos mecanismos alternativos de resolução de conflitos e busca constante para aumentar o desempenho judicial (Gomes \& Guimarães, 2013).

Souza \& Guimarães (2017) analisaram o desenvolvimento e a adoção de inovações pela Justiça Trabalhista brasileira, o impacto e os fatores que facilitam ou dificultam a rotina de trabalho com a adoção do processo judicial eletrônico, a partir da percepção de juízes e gestores 
de tribunais trabalhistas. O estudo destacou a importância do relacionamento entre políticas públicas de infraestrutura e a prestação de serviços com base em Tecnologia da Informação. Entre os impactos relacionados ao processo eletrônico, observou-se que a inovação contribui para o desenvolvimento de outras inovações e mudanças tecnológicas e organizacionais na rotina de trabalho dentro dos tribunais.

Entende-se a partir do presente estudo, que o fomento à criatividade e inovação organizacional é um caminho para o enfrentamento desse contexto de ineficiência institucional. O Poder Judiciário necessita estabelecer mecanismos para incentivar o processo de inovação, em prol da eficiência na prestação de serviços jurisdicionais.

Nesse sentido, vale novamente ressaltar que o trâmite que uma demanda judicial percorre é definido em lei, portanto, sua alteração depende de um processo de extrema complexidade, por, necessariamente, envolver o poder Legislativo.

Já o ambiente organizacional é o mais propício para a mudança, pois depende de fatores mais flexíveis para sua implantação. Assim, o desenvolvimento de capacidades gerenciais, o fomento à criatividade e inovação, a abertura à flexibilização da tradicional hierarquia existente no poder Judiciário, a possibilidade de diálogo com os diversos agentes que estão diretamente envolvidos na prática forense como os serventuários da Justiça, membros da magistratura e Ministério Público, advogados públicos e particulares, usuários em geral.

Nesse sentido, a inovação, concebida como o processo incentivado e organizado com a finalidade de buscar o enfrentamento das mudanças e capaz de viabilizar também o rompimento de paradigmas e a renovação da cultura da organização (Stumpf, 2008), é o caminho para o enfrentamento das diversas deficiências que o sistema de justiça possui.

Com base na literatura já analisada (Armbruster et al., 2008; Damanpour \& Schneider, 2009; Evangelista \& Vezzani, 2010; Frambach \& Schillewaert, 2002; Lam, 2004), entende-se que o fomento à inovação organizacional cumpre a finalidade de criar o ambiente propício ao desenvolvimento de práticas inovadoras que impactem diretamente na eficiência da prestação de serviços jurisdicionais à sociedade brasileira.

Grande exemplo de sucesso na implantação de inovação organizacional foi a definição de metas para o Poder Judiciário, traçadas desde 2009 pelo Conselho Nacional de Justiça (CNJ). As metas impuseram uma rigorosa gestão sobre os processos, especialmente no controle dos fluxos processuais, fomentando um aperfeiçoamento da prestação de serviços jurisdicionais à sociedade brasileira de forma mais célere e eficaz. 
A definição de metas impôs rigoroso controle sobre os processos ajuizados, estabeleceuse julgamento por ordem cronológica (com algumas exceções definidas em leis), a fim de afastar aspectos pessoais que interferiam na pauta de julgamento pelos magistrados, estabeleceu-se uma duração razoável dos processos a fim de se enfrentar os grandes estoques de processos, que, segundo o $\mathrm{CNJ}$, eram os causadores das altas taxas de congestionamento nos tribunais.

A implantação das metas obrigou a uma ampla reorganização administrativa em toda a estrutura do Judiciário, nos tribunais, comarcas e varas, a fim de fiscalizar e executar o cumprimento dos prazos, condições, complexidades processuais, pautas de julgamento, expedição de sentenças e execução. Os tribunais tiveram que ampliar as competências das Corregedorias, com o intuito de efetuar as distribuições e fiscalização de metas entre as comarcas e, estas, por sua vez, necessitaram ser reconfiguradas para permitir a gestão e a execução das metas pelos juízes. As varas necessitaram passar a contar com servidores públicos especializados e capacitados em gestão, a fim de observar o andamento e impulsos processuais, da protocolização à execução da sentença prolatada.

Desta forma, observa-se que as inovações organizacionais promovidas a partir da implantação das metas pelo Conselho Nacional de Justiça propiciaram toda uma melhoria na prestação de serviços jurisdicionais à toda a sociedade brasileira.

Recentemente, pesquisadores conduziram um revisão sistemática da literatura das publicação sobre inovação no setor público do período de 1990 e 2014 (De Vries, Bekkers, \& Tummers, 2016). Nesta pesquisa, De Vries et al. (2014) identificaram que as publicações foram nos seguintes aspectos da inovação no setor público: definições, tipos, antecedentes, objetivos e resultados.

Um resultado interessante desta pesquisa é que os tipos de inovação mais comuns no setor público são inovação administrativa (organizacional) e inovação de processos. Além disso, os autores constatam eu os principais objetivos de iniciativas de inovação no setor público são o aumento de eficácia e eficiência nas práticas de trabalho. Por fim, que o principal motivador de inovação neste setor é pressão do ambiente, em especial da mídia, demanda política e cobrança da população (De Vries, et al., 2016) 
Obviamente, que há obstáculos específicos ao setor público, que dificultam a implementação de inovação. Quanto os obstáculos à inovação na gestão pública brasileira, Brandão e Bruno Faria (2017) identificaram os mais comuns. A figura 2 descreve os principais obstáculos à inovação em gestão pública no Brasil e suas respectivas descrições.

\section{Tabela 2}

Definições das barreiras à inovação em gestão pública

\begin{tabular}{|c|c|}
\hline Barreiras & Definições \\
\hline $\begin{array}{l}\text { Dificuldade de articulação } \\
\text { intersetorial }\end{array}$ & $\begin{array}{l}\text { Dificuldade de coordenação e articulação de políticas públicas de caráter } \\
\text { transversal e intersetorial que envolvem órgãos de diferentes setores. }\end{array}$ \\
\hline Restrições legais & $\begin{array}{l}\text { Exigências legais e normativas que geram obstáculos ao desenvolvimento } \\
\text { de novos procedimentos, produtos, serviços e políticas públicas. }\end{array}$ \\
\hline $\begin{array}{l}\text { Estrutura } \\
\text { verticalizada }\end{array}$ & $\begin{array}{l}\text { Modelo verticalizado de ordenamento e agrupamento de atividades e } \\
\text { recursos que geram estruturas hierárquicas rígidas e podem tornar o } \\
\text { processo de comunicação e de tomada de decisão lentos e ineficientes. }\end{array}$ \\
\hline $\begin{array}{l}\text { Resistência à inovação e aversão ao } \\
\text { risco }\end{array}$ & $\begin{array}{l}\text { Conjunto de hábitos, crenças, valores e atitudes compartilhados pelos } \\
\text { membros da organização e que se expressam pela maneira como os } \\
\text { indivíduos reagem negativamente à inovação. }\end{array}$ \\
\hline $\begin{array}{l}\text { Baixa capacidade técnica de estados } \\
\text { e municípios }\end{array}$ & $\begin{array}{l}\text { Baixo nível de qualificação técnica das equipes de estados e municípios e } \\
\text { infraestrutura física e tecnológica inadequadas ou insuficientes. }\end{array}$ \\
\hline Rotatividade de dirigentes & $\begin{array}{l}\text { Flexibilidade no sistema de seleção de dirigentes que permite a rotatividade } \\
\text { periódica de gestores e, por consequência, dificulta a proposição e a } \\
\text { implementação de inovações. }\end{array}$ \\
\hline $\begin{array}{l}\text { Diversidade social, cultural e econô- } \\
\text { mica do país }\end{array}$ & $\begin{array}{l}\text { Pluralidade de condições culturais, sociais e de desenvolvimento político e } \\
\text { econômico da população em um país de dimensões continentais como o } \\
\text { Brasil. }\end{array}$ \\
\hline $\begin{array}{l}\text { Recursos orçamentários } \\
\text { financeiros limitados }\end{array}$ & $\begin{array}{l}\text { Insuficiência de recursos orçamentários e financeiros para financiamento } \\
\text { de inovações. }\end{array}$ \\
\hline Falta de incentivos à inovação & Falta de apoio e suporte da organização à inovação. \\
\hline
\end{tabular}
Fonte: (Brandão \& Bruno-Faria, 2017, p. 156)

Brandão e Bruno-Faria (2017) concluem que os principais obstáculos mais frequentes na gestão pública brasileiras são: dificuldade de articulação intersetorial, restrições legais, estrutura organizacional verticalizada, resistência à inovação e aversão ao risco, baixa capacidade técnica dos estados e municípios e rotatividade de dirigentes.

Sabendo disso, gestores e dirigentes do setor público precisam atentar ao fato de que é necessário a criação de um ambiente e cultura favoráveis à adoção e implementação de inovação. Nestes aspectos, os principais componentes de uma cultura propícia para a inovação na gestão pública são a criação de equipes multidisciplinares, possibilidade de experimentação, suporte da liderança, incentivo de criação de conhecimento colaborativa e coletiva, gestão do conhecimento, e implementação de programas de incentivo e de treinamento, que fomentem a prática de inovação junto aos colaboradores. 


\section{Considerações Finais}

Diante dos inúmeros desafios postos ao Poder Judiciário no Brasil, no cumprimento das suas diversas competências legais, atendendo os princípios constitucionais da eficiência e celeridade processual, entende-se que se faz necessário o fomento à criatividade e à inovação organizacional como forma de enfrentamento desse contexto de ineficiência institucional. Por este motivo, este ensaio teórico explorou o tema da inovação organizacional e de sua adoção e implementação no Poder Judiciário brasileiro, para melhoria da prestação de serviços jurisdicionais.

O Poder Judiciário necessita estabelecer mecanismos internos para incentivar o processo de inovação organizacional, em prol da eficiência na prestação de serviços jurisdicionais, que sejam capazes de estabelecer significativas mudanças na cultura organizacional, no rompimento de paradigmas fortemente marcados pela hierarquia e pelo costume, possibilitem um maior diálogo entre os sujeitos envolvidos no exercício da atividade jurisdicional.

Certamente, implementar inovação organizacional na gestão pública brasileira é um grande e complexo desafio (Cavalcante \& Camões, 2017). Todavia, a inovação é fundamental para que órgãos públicos possam melhorar o atendimento à população e também suprir as necessidades da sociedade (De Vries et al., 2016).

Por se tratar de um ensaio teórico, este estudo se limita a explanação teórica sobre tema da inovação organizacional no Poder Judiciário, sem se ater a um método de seleção e análise de publicações sobre o tema, como uma revisão sistemática literatura (Petticrew \& Roberts, 2006) ou análise bibliométrica (Zupic \& Carter, 2015).

Para o futuro, há necessidade de condução de mais estudos de caso sobre implementação de inovação nas diversas ramos da gestão pública: ambiental, infraestrutura e social, a fim de identificar os facilitadores e obstáculos específicos de cada ramo (Cavalcante \& Camões, 2017).

Outra sugestão para pesquisas futuras é adoção de métodos quantitativos em pesquisas de inovação do setor público, uma vez que esta área de pesquisa tem sida dominada por estudos com abordagem qualitativa. Pesquisadores têm um amplo campo para desenvolverem novas teorias, desde que bem embasadas e validadas, assim como para desenvolver estudos de comparação de resultados entre diferentes países e setores da gestão pública (De Vries et al., 2016). 
Por fim, observamos que a gestão pública brasileira carece de pesquisas que possam responder a questões como: quais os antecedentes e obstáculos institucionais da inovação no setor público, criação de indicadores e medidores do impacto e desempenho de inovação na gestão pública (Camões et al., 2017).

\section{Referências}

Abramo, C. W. (2010). Tempos de espera no Supremo Tribunal Federal. Retrieved from http://direitosp.fgv.br/node/2447

Araújo, C. C. S. de A., Modolo, D., \& Carneiro Jr., E. (2018). Identificação e categorização das principais referências usadas em publicações em inovação organizacional. Revista Brasileira de Gestão E Inovação, 5(2), 132-158.

Armbruster, H., Bikfalvi, A., Kinkel, S., \& Lay, G. (2008). Organizational innovation: The challenge of measuring non-technical innovation in large-scale surveys. Technovation, 28(10), 644-657. https://doi.org/10.1016/j.technovation.2008.03.003

Birkinshaw, J. M., Hamel, G., \& Mol, M. (2008). Management innovation. Academy of Management Review, 33(4), 825-845. https://doi.org/10.5465/AMR.2008.34421969

Bonavides, P. (2011). Curso de Direito Constitucional. São Paulo: Malheiros.

Brandão, S. M., \& Bruno-Faria, M. de F. (2017). Barreiras à Inovação em Gestão em Organizações Públicas do Governo Federal Brasileiro: Análise e percepção de Dirigentes. In P. Cavalcante, M. Camões, B. Cunha, \& W. Severo (Eds.), Inovação no Setor Público: Teoria, Tendências e Casos no Brasil (p. 266). Brasília: Instituto de Pesquisa Econômica Aplicada - IPEA.

Camisón, C., \& Villar-López, A. (2011). Non-technical innovation: Organizational memory and learning capabilities as antecedent factors with effects on sustained competitive advantage. Industrial Marketing Management, 40(8), 1294-1304. https://doi.org/10.1016/j.indmarman.2011.10.001

Camisón, C., \& Villar-López, A. (2014). Organizational innovation as an enabler of technological innovation capabilities and firm performance. Journal of Business Research, 67(1), 2891-2902. https://doi.org/10.1016/j.jbusres.2012.06.004

Camões, M. R. de S., Severo, W. da R., \& Cavalcante, P. (2017). Inovação na Gestão Pública Federal: 20 anos do prêmio inovação. In P. Cavalcante, M. Camões, B. Cunha, \& W. Severo (Eds.), Inovação no Setor Público: Teoria, Tendências e Casos no Brasil (p. 266). Brasília: Instituto de Pesquisa Econômica Aplicada - IPEA.

Canotilho, J. J. G. (2003). Direito Constitucional e Teoria da Constituição. Coimbra: Almedina.

Castro, A. S. (2011). Indicadores Básicos e Desempenho da Justiça Estadual de Primeiro Grau no Brasil. Retrieved from http://www.ipea.gov.br/portal/index.php?option=com_content $\&$ view=article \&id=9605

Cavalcante, P., \& Camões, M. (2017). Inovação no Setor Público: Avanços e Caminho a Seguir no Brasil. In P. Cavalcante, M. Camões, B. Cunha, \& W. Severo (Eds.), Inovação no Setor Público: Teoria, Tendências e Casos no Brasil (p. 266). Brasília: Instituto de Pesquisa Econômica Aplicada - IPEA.

Chiovenda, G. (2002). Instituições de Direito Processual Civil - Volume II. Campinas: Bookseller.

CNJ. (2016). Justiça em números 2016: Ano-base 2015. Brasília.

Daft, R. L. (1978). A dual-core model of organizational innovation. Academy of Management 
Journal, 21(2), 193-210.

Damanpour, F. (1991). Organizational innovation: A meta-analysis of effects of determinants and moderators. Academy of Management Journal, 34(3), 555-590. https://doi.org/10.2307/256406

Damanpour, F., \& Aravind, D. (2011). Managerial Innovation: Conceptions, Processes, and Antecedents. Management and Organization Review, 2(8), 1-32. https://doi.org/10.1111/j.1740-8784.2011.00233.x

Damanpour, F., \& Evan, W. M. (1984). Organizational and performance: The problem of “organizational lag." Administrative Science Quarterly, 29(3), 392-409.

Damanpour, F., \& Schneider, M. (2009). Characteristics of Innovation and Innovation Adoption in Public Organizations: Assessing the Role of Managers. Journal of Public Administration Research and Theory, 19(3), 495-522. https://doi.org/10.1093/jopart/mun021

De Vries, H., Bekkers, V., \& Tummers, L. (2016). Innovation in the public sector: A systematic review and future research agenda. Public Administration, 94(1), 146-166. https://doi.org/10.1111/padm.12209

Dobrowolski, S. (1990). Novas Funções e Estrutura do Poder Judiciário na Constituição de 1988: Uma Introdução. Retrieved from http://www2.senado.leg.br/bdsf/handle/id/175812

Evangelista, R., \& Vezzani, A. (2010). The economic impact of technological and organizational innovations: A firm-level analysis. Research Policy, 39(10), 1253-1263.

Fachada, P., Figueiredo, L. F., \& Lundberg, E. (2003). Notas Técnicas do Banco Central do Brasil (n. 35 - maio). Brasília.

Fraisse, H., Kramarz, F., \& Prost, C. (2009). Labor court inputs, judicial cases outcomes and labor flows: Identifying real EPL. Paris.

Frambach, R. T., \& Schillewaert, N. (2002). Organizational innovation adoption: A multi-level framework of determinants and opportunities for future research. Journal of Business Research, 55(2), 163-176. https://doi.org/10.1016/S0148-2963(00)00152-1

Gomes, A.O., \& Guimarães, T.A. (2013). Desempenho no Judiciário: conceituação, estado da arte e agenda de pesquisa. Revista de Administração Pública, 47(2), 379-401.

Hwang, A.-S. (2004). Integrating technology, marketing and management innovation. Research-Technology Management, 47(4), 27-31. https://doi.org/10.1177/135050849743007

Kimberly, J. R., \& Evanisko, M. J. (1981). Organizational innovation: the influence of individual, organizational and contextual factors on hospital adoption of technological and adminstrative innovations. Academy of Management Journal, 24(4), 689-713. https://doi.org/10.2307/256170

Knight, K. E. (1967). A descriptive model of the intra-firm innovation process. The Journal of Business, 40(4), 478-496. https://doi.org/10.1086/521238

Lam, A. (2004, April). Organizational Innovation [MPRA Paper].

Lewandowski, E. R. (2009). O protagonismo do Poder Judiciário na era dos direitos. Revista de Direito Administrativo, 251(0), 77-85.

Mansfield, E. (1994). Intellectual Property Protection, Foreign Direct Investment, and Technology Transfer (No. 19). Washington, D.C.

Mansfield, E. (1995). Intellectual property protection, direct investment, and technology transfer: Germany, Japan, and the United States (No. 27). Washington, D.C.

Marmelstein, G. (2013). Curso de Direitos Fundamentais. São Paulo: Atlas.

Medeiros, M.J.S.P. de. (2006). Inovações na administração e funcionamento da justiça federal - um novo juiz para um novo poder. Revista CEJ, n. 33, 62-71. 
Meyer, A. D., \& Goes, J. B. (1988). Organizational assimilation of innovations: A multilevel contextual analysis. Academy of Management Journal, 31(4), 897-923. https://doi.org/10.2307/256344

Morais, A. (2001). Constituição do Brasil Interpretada e Legislação Constitucional. São Paulo: Atlas.

OECD. (2005). Oslo Manual - Guidelines for Collecting and Interpreting Innovation Data (Third Edition). Paris, France: OECD.

Petticrew, M., \& Roberts, H. (2008). Systematic reviews in the social sciences: A practical guide. John Wiley \& Sons.

Sadek, M. T. (2004). Judiciário: Mudanças e reformas. Estudos Avançados, 18(51), 79-101.

Sousa, M.M., \& Guimarães, T.A. (2017). The adoption of innovations in Brazilian labour courts from the perspective of judges and court managers. Revista de Administração, 52, 103-113.

Stumpf, J. da C. (2008). Poder judiciário: Morosidade e inovação. Fundação Getúlio Vargas FGV.

Taylor, M. M. (2005). Citizens against the State: the riddle of high impact, low functionality courts in Brazil. Brazilian Journal of Political Economy, 25(4), 418-438.

Zupic, I., \& Čater, T. (2015). Bibliometric methods in management and organization. Organizational Research Methods, 18(3), 429-472. http://doi.org/10.1177/1094428114562629 